\title{
Sociability behavior and the social environment
}

HARRY P. SHELLEY AND KERMIT T. HOYENGA

THE UNIVERSITY OF NEBRASKA

The relationship between social living and sociability was studied in two experiments. The $S s^{\prime}$ social living conditions, established at weaning, were reversed $48 \mathrm{~h}$ prior to testing. Variations in sociability occur in the mature rat after 2-5 days of changed conditions and can be reversed by changes in social living conditions. Isolated Ss have higher sociability scores. If the differences in sociability are due to stimulus habituation, recency appears to be more important than frequency.

Lindzey et al (1965) have defined sociability as the time spent next to caged display animals in opposite corners of an open field. Shelley \& Hoyenga (1966) have shown that mature rats reared in social isolation since weaning will, over a series of trials, spend more time near display animals than will rats reared from weaning in groups of eight or nine. Aside from the problem of the nature of the intervening processes, just how variations in social living conditions are related to differences in sociability is not known. Several questions, however, immediately come to the fore. (1) Are differences in sociability a function of more general deprivation effects associated with the operations defining social deprivation? The cage life of the socially isolated animal is not very stimulating. Although the animal has considerable territory in which to move about, it has a very homogeneous environment with little novel, varying, or complex stimuli. Thus there may be more general deprivation effects. (2) Are the effects tied to "early experience" albeit a limited "post-weaning early experience?" (3) How long must the social living conditions last to produce their effect on sociability? (4) Are the effects reversible? Two experiments were conducted to provide some answers to the above questions. Subjects and Apparatus

Holtzman Sprague-Dawley rats were placed at weaning either singly or in groups of eight in $38 \times 12 \times$ 12 in. cages. Food and water consumption was ad lib. In Experiment $1 \mathrm{Ss}$ were males $(\mathrm{N}=32)$ and were 85 days old at testing; in Experiment 2 Ss were females $(\mathrm{N}=32)$ and were 95 days old at testing. All display animals were males in Experiment 1 and females in Experiment 2. As in the previous studies, the $4 \times 4$ ft open field was constructed of $5 / 8 \mathrm{in}$. plywood painted a flat medium gray with 12 in. sides. The floor was lightly covered with Sani-cell (Experiment 1) or sawdust (Experiment 2). The display cages were placed in the four corners of the open field and were $8 \times 8 \times 8$ in. with 1/2 in. hardware cloth screening on all four sides. The only light source was a $40 \mathrm{~W}$ bulb 48 in. above the center of the floor.

\section{Procedure}

A line was drawn on the floor 6 in. away from the two exposed sides of all display cages. When $\mathrm{S}$ placed both forefeet inside the line, he was adjudged adjacent to the cage. An observer with two stop watches recorded the time spent adjacent to the occupied and empty cages. The occupied cages were in diagonally opposite corners. The location of the occupied display cages was alternated for successive Ss (Experiment 1) or successive trials (Experiment 2). On each trial, $S$ was placed in the center of the open field and allowed to run freely for $5 \mathrm{~min}$. Only one trial was given per day.

In Experiment 1, living conditions were reversed for half the Ss, i.e., Ss in one group cage were caged singly and eight singly reared Ss were caged together. Forty-eight $h$ later test trials were begun for all Ss. In Experiment 2, the procedure was the same except that (1) all Ss were given five trials in the open field prior to the reversal of living conditions, (2) immediately following the fifth trial, Ss in one group cage were placed singly in cages and eight singly reared Ss were placed together in a cage, and (3) $48 \mathrm{~h}$ after the reversal of living conditions all Ss were given three additional trials in the open field.

\section{Results}

For convenience of communication the original rearing conditions will be identified as the pre-living condition and the reversed living condition as the post-living condition.

Experiment 1. Analysis of variance of the data plotted in Fig. 1 indicates two sources of variance. There is a significant main effect due to post-living conditions $(F=11.35, \mathrm{df}=1 / 28, \mathrm{p}<.01)$ and a significant post-living condition by trials interaction $(F=$

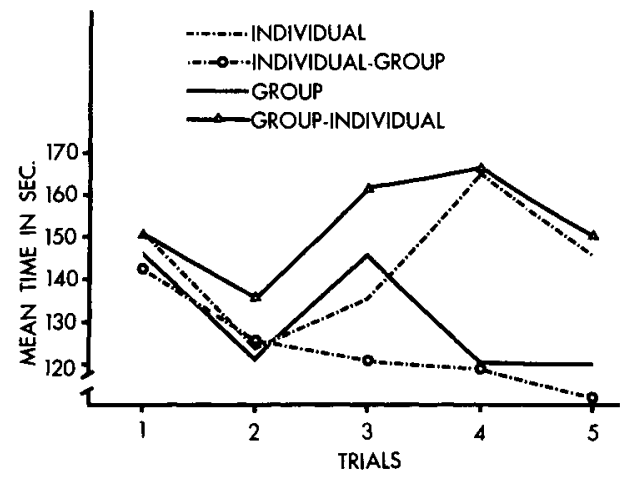

Fig. 1. Experiment 1. Sociability behavior as a function of pre-living conditions and post-living conditions. 


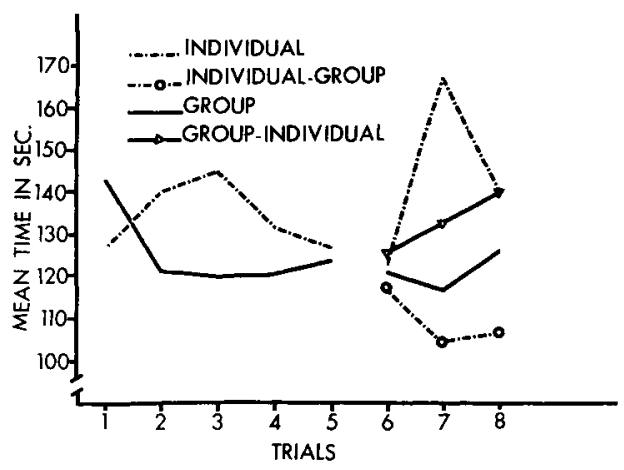

Fig. 2. Experiment 2. The reversibility of sociability behavior.

3.76, $\mathrm{df}=4 / 112, \mathrm{p}<.01)$. No significant effect was produced by the 63 days of pre-living conditions, i.e., $48 \mathrm{~h}$ of post-living conditions substituted for 63 days of pre-living conditions.

Experiment 2. Figure 2 further illustrates the significance of immediate past experience rather than the longer term effects of the pre-living conditions. The first part of the figure shows, essentially, the effect of post-weaning living conditions upon sociability behavior previously described (Shelley \& Hoyenga, 1966). The last part of the figure (Trials $6-8$ ) shows the same effect produced after only $48 \mathrm{~h}$ of living either in social isolation or in groups of eight. The analysis of variance on Trials 6-8 indicates a significant main effect due to the post-living conditions $(\mathrm{F}=7.03, \mathrm{df}=1 / 28, \mathrm{p}<.05)$ and a trials by post-living conditions interaction $(F=4.29, \mathrm{df}=2 / 56$, $\mathrm{p}<.05)$. Again the pre-living condition contributes no effect over and above that produced by $48 \mathrm{~h}$ of reversed living conditions.

In neither experiment was there any evidence of emotionality as defined by freezing or defecation. Within the limits of these operations emotionality was not a factor in the open field behavior of the Ss. As in the previous studies there are no systematic differences among the experimental groups with respect to time by the empty cages.

\section{Discussion}

Several implications follow rather immediately from the findings:

(1) Variations in sociability behavior are not tied to the immediate post-weaning period. To the degree that immediate post-weaning experience is early experience, early experience is not crucial.
(2) Variations in sociability behavior can be produced by as little as 2 to 5 days of modified social living conditions rather than the 60 to 90 days previously employed.

(3) The effects of social living conditions on sociability behavior are reversible. Levels of sociability behavior once established can be reversed when appropriate changes in social living conditions are introduced.

(4) The reversibility of sociability scores indicates that the greater sociabllity associated with social isolation is not a matter of a more general impairment of the socially deprived S's performance due to general deprivation effects associated with social isolation.

(5) According to Berlyne (1960) novel stimuli or complex stimuli have the property of receiving attention and directing investigative behavior. Berlyne's habituation hypothesis holds that repeated exposure to a stimulus reduces or eliminates the tendency of an organism to respond selectively to that stimulus and the reduced sociability scores of the group reared rats may be due to this factor. If such is the case the data on reversed living conditions indicate that recency may be more important than frequency in determining habituation.

It is not yet clear what the motivational variable involved in sociability behavior is. Short-term social deprivation is sufficient to produce the behavior, but whether or not the social element qua social is essential or not remains unclear. It may well be advisable to speak of sociability behavior rather than sociability, thus making clear that the relationships established are with reference to S's behavior and the external stimuli involved in that behavior. The nature of the intervening motivational process remains unclear.

\section{References}

Berlyne, D. E. Conflict, arousal, and curiosity. New York: McGrawHill, 1960.

Lindzey, G., Winston, H. D., \& Roberts, L. E. Sociability, fearfulness, and genetic variation in the mouse. J. abnorm. soc. Psychol., 1965, 1, 642-645.

Shelley, H. P., \& Hoyenga, k. T. Rearing and display variables in sociability, Psychon. Sci., 1966, 5, 11-12.

Note

1. A portion of this paper was read at the annual meeting of the Nebraska Academy of Sciences, April, 1966. 